\title{
The functional alteration of mutant GFAP depends on the location of the domain: morphological and functional studies using astrocytoma-derived cells
}

\author{
Tomokatsu Yoshida $\cdot$ Yasuko Tomozawa • \\ Takayo Arisato · Yuji Okamoto · Hirofumi Hirano • \\ Masanori Nakagawa
}

Received: 27 October 2006/ Accepted: 30 January 2007/ Published online: 22 February 2007

(C) The Japan Society of Human Genetics and Springer 2007

\begin{abstract}
To clarify the functional effects of mutant glial fibrillary acidic protein (GFAP), we examined the expression patterns of mutant GFAPs (V87G, R88C, and $\mathrm{R} 416 \mathrm{~W}$ ) in astrocytoma-derived cells and performed migration assay. The morphological change was found in mutant GFAP cells, although the number of changes was small. On migration assay, the migration rate in cells with the V87G or R88C mutation, which are located in the helical rod domain in GFAP, was significantly higher than those of wild-type and R416W. These findings suggest that the functional abnormalities of astrocytes might be induced prior to aggregation of GFAP in Alexander disease and that the functional alteration depends on the location of the domain.
\end{abstract}

Keywords Alexander disease - GFAP mutation . Migration assay $\cdot$ Immunocytochemistry ·

Astrocytoma-derived cells

T. Yoshida $\cdot$ Y. Tomozawa $\cdot$ M. Nakagawa $(\bowtie)$

Department of Neurology,

Graduate School of Medical Science,

Kyoto Prefectural University of Medicine,

Kawaramachi Hirokoji, Kajii-chou 465,

Kamigyo-ku, Kyoto 602-0841, Japan

e-mail: mnakagaw@koto.kpu-m.ac.jp

T. Arisato - Y. Okamoto

Department of Neurology and Geriatrics,

Kagoshima University Graduate School of Medical

and Dental Sciences, Kagoshima University,

Kagoshima, Japan

H. Hirano

Department of Neurosurgery,

Kagoshima University Graduate School of Medical and Dental Sciences,

Kagoshima University, Kagoshima, Japan

\section{Introduction}

Alexander disease is a rare neurodegenerative disorder characterized by white-matter degeneration, and the formation of cytoplasmic inclusions called Rosenthal fibers can be demonstrated in astrocytes on pathological studies (Alexander 1949). Rosenthal fibers, which accumulate particularly in astrocyte end-feet in the subpial and perivascular zones, consist of glial fibrillary acidic protein (GFAP), heat shock protein 27 and $\alpha \mathrm{B}$ crystallin (Johnson and Bettica 1989; Tomokane et al. 1991; Iwaki et al. 1989). Clinically, Alexander disease is classified into three subtypes: infantile, juvenile, and adult forms, based on the age at disease onset. Recently, GFAP mutations have been reported in various forms of Alexander disease (Brenner et al. 2001; Aoki et al. 2001; Rodriguez et al. 2001; Shiroma et al. 2001; Gorospe et al. 2002; Li et al. 2002; Meins et al. 2002; Namekawa et al. 2002; Probst et al. 2003; Sawaishi et al. 2002; Shiihara et al. 2002; Shiroma et al. 2003; Suzuki et al. 2004) and we have identified juvenile and adult forms of Alexander disease with three different GFAP mutations: V87G (Okamoto et al. 2002), R88C (Nobuhara et al. 2004) and R416W (Kinoshita et al. 2003). To date, there had been few reports investigating the properties of mutant GFAP (Li et al. 2005; Hsiao et al. 2005; Perng et al. 2006). However, there have not been any reports investigating the dynamic functional effects of mutant GFAP in astrocytes.

In this study, we prepared vectors of the three different GFAP mutations, investigated the expression pattern of mutant GFAPs in astrocytoma-derived cells and performed migration assay to examine the dynamic functional effects of these mutant GFAPs in astrocytes. 


\section{Materials and methods}

\section{Vector construction}

The coding region of human genomic DNA was amplified by the polymerase chain reaction (PCR). After purification, the PCR products were digested with EcoRI and BamHI and ligated into the EcoRI and BamHI site of pUC18 plasmid (Takara Shuzo, Otsu, Japan). Point mutations [V87G (GFAP T274G), R88C (GFAP C276T), R416W (GFAP C1260T)] were generated as described for long and accurate (LA) PCR in vitro mutagenesis kit (Takara Shuzo, Otsu, Japan). Following digestion with EcoRI and SphI, each of the mutated DNA fragments was ligated into the $E c o$ RI and SphI site of pUC18. Each of the pUC18 plasmids containing mutant GFAP was amplified by PCR using the following primers with restriction sites: sense, GFAP-F/HindIII 5'-CGGAAGCTTCTAGCA GGATGGAGAGGAGAC-3'; antisense, GFAP-R/ Bam 5'-GAGGATCCCAGAGGCCACCAGGTGG GTC-3'. After purification, the PCR products were digested with HindIII and BamHI and ligated into the HindIII and BamHI site of pREP4 plasmid (Invitrogen, Sandiego, CA, USA). The constructs were sequenced using an ABI PRISM 310 autosequencer (PE Applied Biosystems, Foster City, CA, USA).

To construct GFAP tagged with GFP vector, each of the pUC18 plasmids containing mutant GFAP was amplified by PCR using the following primers with restriction sites: sense, GFAP-F/Hind-GFP 5'CGAAGCTTGATTACGAATTCAGCAGG-3'; antisense: GFAP-R/pAcGFP-Bam 5'-GAGGATCCGTC CTGCCTCACATCACA-3'. After purification, the PCR products were digested with HindIII and BamHI and ligated into the HindIII and BamHI site of pAcGFP-C3 (Becton Dickinson, Franklin Lakes, NJ, USA).
Cell culture

Human astrocytoma-derived cells (mtU251) were used in this study. Originally, this cell line was a U251 cell, which originally expressed GFAP protein. However, GFAP was no longer expressed spontaneously during the process of culture. Western blotting was performed in order to confirm that GFAP was not expressed at all in crude mtU251 cells line (Fig. 1). mtU251 cells were grown in RPMI 1640 medium (Nikken Biochemical Laboratory, Kyoto, Japan) supplemented with $10 \%$ fetal bovine serum (FBS) and amphotericin B $(0.125 \mu \mathrm{g} / \mathrm{ml})$.

\section{Western blotting}

About $1 \times 10^{7}$ cells were washed twice with $1 \times$ phosphate buffered saline (PBS) and extracted with $0.5 \%$ $\mathrm{v} / \mathrm{v}$ Triton X-100, $2 \mathrm{mM}$ ethylenediamine- $, \mathrm{N}, \mathrm{N}^{\prime}, \mathrm{N}^{\prime}$ tetraacetic acid (EDTA), $2 \mathrm{mM}$ phenylmethylsulfonyl fluoride, $\mathrm{pH} \mathrm{7.2,} \mathrm{on} \mathrm{ice} \mathrm{for} 15 \mathrm{~min}$. The extracts were spun on a microfuge at $4^{\circ} \mathrm{C}$ for $10 \mathrm{~min}$ at $16,000 \mathrm{~g}$. The supernatants were collected. Protein concentrations were determined using the bicinchoninic acid (BCA) protein assay kit (Pierce, Rockford, IL, USA). Seven to $15 \mu \mathrm{g}$ protein each from the soluble and insoluble fractions was diluted in sample buffer. Then, the samples were electrophoresed and transferred to an immobilin polyvinylidene fluoride membrane (Millipore, Bedford, MA, USA) following Millipore's recommendations. After being washed in blocking solution, the blots were incubated for $2 \mathrm{~h}$ at room temperature with a polyclonal antibody for GFAP (Santa Cruz Biotechnology, Santa Cruz, CA, USA) at a dilution of 1/1,000. After being washed with PBS-Tween-20 (PBT), the blots were incubated with horseradish-peroxidase-conjugated anti-rabbit secondary antibody at a dilution of $1 / 2,000$ for $1 \mathrm{~h}$ at room temperature (Santa Cruz).

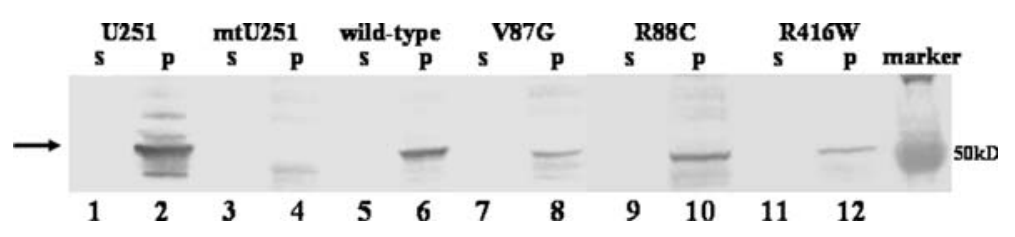

Fig. 1 Western blotting of GFAP protein obtained from astrocytoma-derived cells. Lane 1, 2 positive control (U251 cell). Lane 3, $4 \mathrm{mtU} 251$ cells. Lane 5, $6 \mathrm{mtU} 251$ cells transfected with wild-type GFAP. Lane 7, $8 \mathrm{mtU} 251$ cells transfected with V87G GFAP. Lane 9, $10 \mathrm{mtU} 251$ cells transfected with R88C GFAP. Lane 11, 12 mtU251 cells transfected with R416W GFAP. Lane $S$ supernatant fraction. Lane $P$ pellet fraction after centrifugation at $16,000 \mathrm{~g}$. The pellet lanes showed that GFAP was not expressed in mtU251 cells only. GFAP was negative in all the supernatant lanes. U251 cells [IFO50285 U-251 MG(KO)] were obtained from the Health Science Research Resources Bank, Osaka, Japan 
Bands were visualized with nitrotetrazolium blue (POD immunostain set; Wako, Osaka, Japan).

\section{Transfection}

\section{Transient transfection}

The day before transfection, two-well chamber slides (42 $\mathrm{cm}^{2} /$ well) (Nalge Nunc International, NY, USA) were coated with poly-L-lysine for $6 \mathrm{~h}(0.04 \mathrm{mg} / \mathrm{ml}$ in $1 \times$ PBS). Then, $8 \times 10^{4}$ cells per well, $4 \times 10^{4}$ cells per well or $2 \times 10^{4}$ cells per well were plated onto each chamber for staining at 24,48 or $72 \mathrm{~h}$ after transfection, respectively. Cells in each chamber were transfected for $2 \mathrm{~h}$ using $1.5 \mu \mathrm{g}$ plasmid with SuperFect transfection reagent (QIAGEN, Tokyo, Japan). At the end of the transfection, cells were washed with medium containing $10 \%$ FBS to terminate the reaction. Twenty-four hours, $48 \mathrm{~h}$ or $72 \mathrm{~h}$ after transfection, cells in the chamber were washed with $1 \times$ PBS and fixed with cold methanol at $-20^{\circ} \mathrm{C}$ for $20 \mathrm{~min}$, then air-dried and stored at $-20^{\circ} \mathrm{C}$.

\section{GFP transfection}

Two days before transfection, $1 \times 10^{5}$ cells were plated onto $35 \mathrm{~mm}$ plates (Becton Dickinson, Franklin Lakes, NJ, USA). Cells on each chamber were transfected for $2 \mathrm{~h}$ using $2.0 \mu \mathrm{g}$ plasmid with SuperFect Transfection reagent. At the end of transfection, cells were washed with medium containing $10 \%$ FBS to terminate the reaction. Cells were assayed for expression of the transfected gene after $48 \mathrm{~h}$. Two days after transfection, appropriate cells were selected after the addition of $1.0 \mathrm{mg} / \mathrm{ml} \mathrm{G} 418$ (Sigma, St. Louis, MO, USA).

Fluorescence immunocytochemistry

After dehydration in tris-buffered saline (TBS) at room temperature for $20 \mathrm{~min}$, the cells were blocked for 20 min with $1 \%$ normal goat serum in TBS at $25^{\circ} \mathrm{C}$. We used anti-cow GFAP as the primary antibody at a dilution of $1 / 500$, and Alexa Fluor ${ }^{\circledR} 488$ conjugated goat anti-rabbit IgG (Molecular Probes, OR, USA) as a secondary antibody at a dilution of $1 / 1,000$. All immunocytostaining procedures were performed at $25^{\circ} \mathrm{C}$ unless stated otherwise. Cells were incubated for 30 min with primary antibody. After washing with TBS, cells were incubated for $30 \mathrm{~min}$ with secondary antibody. The cells were mounted in Vectashield (Vector Laboratories, CA, USA).

Following immunostaining of GFAP, to examine whether the transfected cells have the ability to proliferate, immunostaining of proliferating cell nuclear antigen (PCNA) was performed. The cells were rehydrated with $1 \times$ PBS at room temperature for $5 \mathrm{~min}$. Then, the cells were blocked with $3 \%$ hydrogen peroxide with ethanol for $15 \mathrm{~min}$. We used PC10 (mouse monoclonal anti-PCNA, Nichirei, Tokyo, Japan) as the primary antibody, and Alexa Fluor $555^{\circledR}$ conjugated goat anti-mouse IgG (Molecular Probes, OR, USA) as the secondary antibody at a dilution of $1 / 2,000$. All immunocytostaining procedures were performed at $25^{\circ} \mathrm{C}$. Cells were incubated for $60 \mathrm{~min}$ with primary antibody. After washing with PBS, cells were incubated for $30 \mathrm{~min}$ with secondary antibody. The cells were mounted in Vectashield.

Stained cells were viewed using an Olympus BX61 confocal microscope or IX70 fluorescence microscope. Between 500 and 800 transfected cells were independently counted by two examiners using an Olympus IX70 at a magnification of $200 \times$.

We performed statistical analysis on the proportions of the filamentous pattern and aggregate or amorphous pattern found in each transfected cells using commercially available software $\left(\mathrm{JMP}^{\circledR}\right)$. Pearson's $\chi^{2}$ test was used to compare differences between pairs of different mutant GFAPs.

\section{Migration assay}

For migration assay, $1 \times 10^{5}$ GFP-wild type, GFP-V87G GFAP, GFP-R88C GFAP or GFP-R416W GFAP cells in $300 \mu$ RPMI 1640 medium without serum were added to the culture insert with an $8 \mu \mathrm{m}$-pore fluorescence blocking micropore (FBM) membrane (HTS FluoroBlok $^{\mathrm{TM}}$ Inserts, Becton Dickinson, Franklin Lakes, NJ, USA). The culture insert was set on a 24-well plate containing $700 \mu \mathrm{l}$ RPMI 1640 medium containing $10 \% \mathrm{FBS}$, and incubated for $8 \mathrm{~h}$ in a $\mathrm{CO}_{2}$ incubator at $37^{\circ} \mathrm{C}$. The same experiment was repeated four times. The invading cells were visualized under the Olympus IX70 microscope at a magnification of 100×. Up to four different fields were counted for each condition after recording every well with a resolution of $1,392 \times 1,024$ per channel. The migrated cells per field recognized by time were compared by regression analysis using $\mathrm{JMP}^{\circledR}$. The Tukey-Kramer honestly significant difference (HSD) test was applied to the comparison of the velocity of migration between a pair of different plasmids.

\section{Results}

Morphological analysis

mtU251 cells without transfection were never stained by anti-GFAP antibody (data not shown). There was no 
difference in the cell doubling time among cells transfected with different GFAP mutations. The transfected cells could be classified into three patterns of GFAP expression: filamentous pattern, polarized distribution pattern and aggregate or amorphous pattern (Fig. 2). Filamentous pattern appeared to be a fundamentally normal GFAP structure in both wild-type and mutant GFAP (Fig. 2a, c, e, g). Polarized distribution pattern was also observed in both wild-type GFAP and mutant GFAPs (Fig. 2b). This pattern showed bipolar distribution of GFAP in the mitotic process with filaments between the bipoles when viewed with a confocal microscope and local distribution after mitosis. In this pattern, the bipolar distribution was stained with PCNA, which plays a fundamental role in DNA replication and repair (Fig. 3b). Aggregate or amorphous pattern showed irregular aggregation of GFAP with few filamentous structures or appeared to be cells whose filament networks were destroyed (Fig. 2d, f, h). The cells with an aggregate pattern or amorphous pattern were not stained by anti-PCNA (Fig. 3c). The most critical findings were that the aggregate pattern or amorphous pattern was observed more frequently in cells transfected with mutant GFAPs than in wild-type GFAP $(P<0.01)$ (Fig. 4). However, there was no significant difference in the proportion of aggregate and amorphous patterns among mutant GFAPs (Fig. 4). The distribution patterns and anti-PCNA staining proportion observed 24 and $48 \mathrm{~h}$ after transfection were similar to those $72 \mathrm{~h}$ after transfection.

\section{Migration assay}

All kinds of transfected cells migrated time dependently and the relation between the migration rate and time could be shown as a linear function (data not
Fig. 2 Immunocytochemistry of wild-type and mutant GFAPs stained with polyclonal antibody for GFAP (green color). a, b Cells transfected with wildtype GFAP. a Filamentous pattern, which could not be distinguished from a normalappearing filamentous GFAP structure. b Polarized distribution pattern, which showed polar distribution of GFAP in mitosis. c, d Cells transfected with V87G. e, $\mathbf{f}$ Cells transfected with R88C. $\mathbf{g}, \mathbf{h}$ Cells transfected with R416W. c, e, $\mathbf{g}$ A filamentous pattern, which was observed in about $97 \%$ of mutant GFAPs. d, f, h Aggregate or amorphous pattern, which showed irregular aggregation of GFAP with a few filamentous structures or appeared to be cells whose filament networks were destroyed
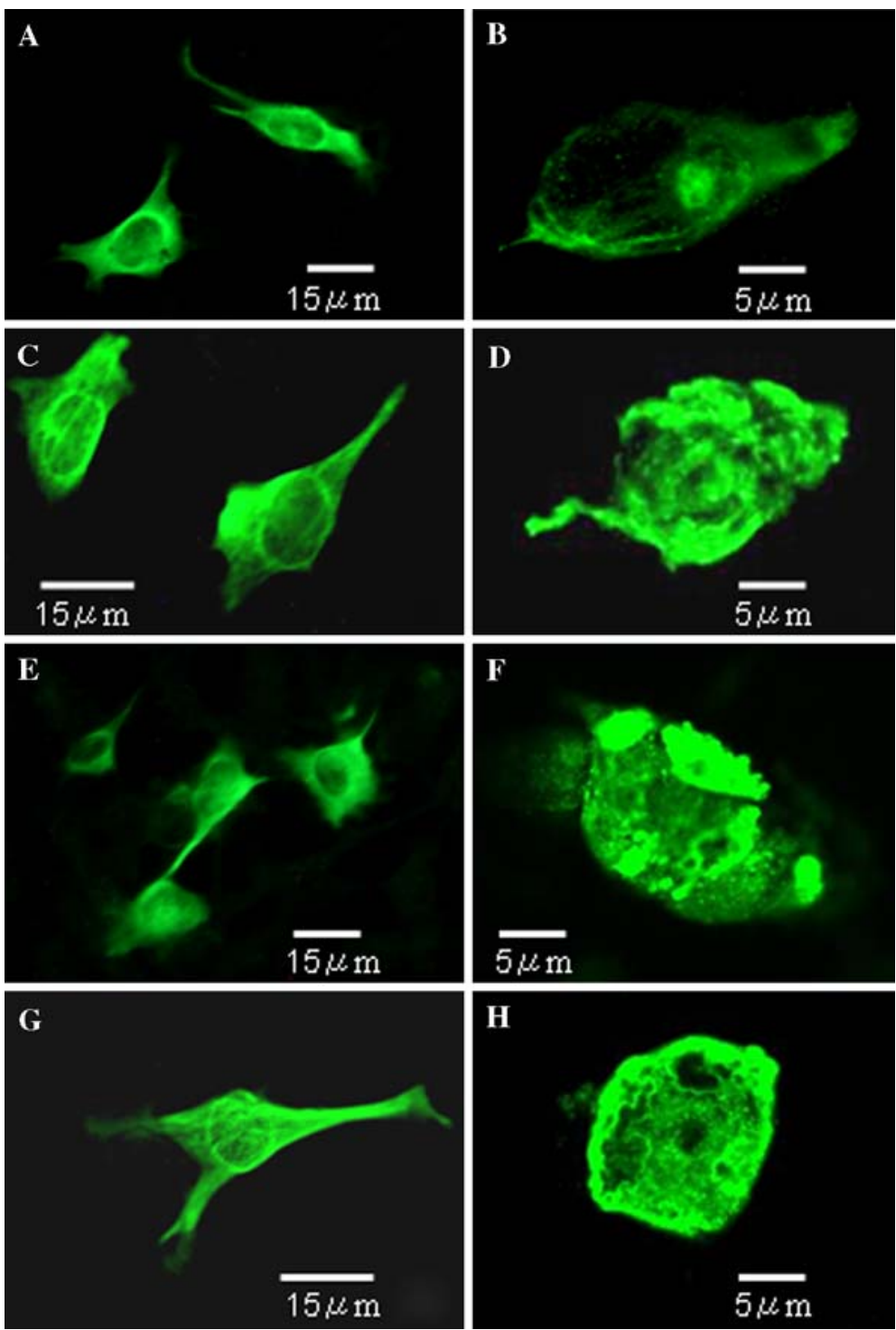

H

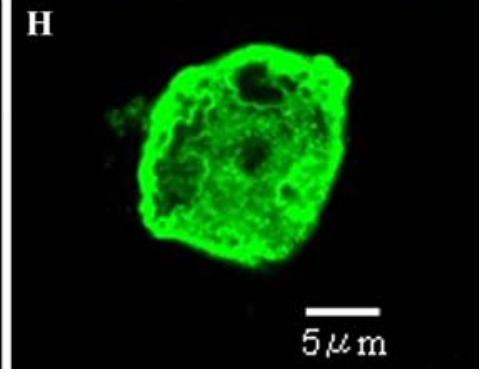



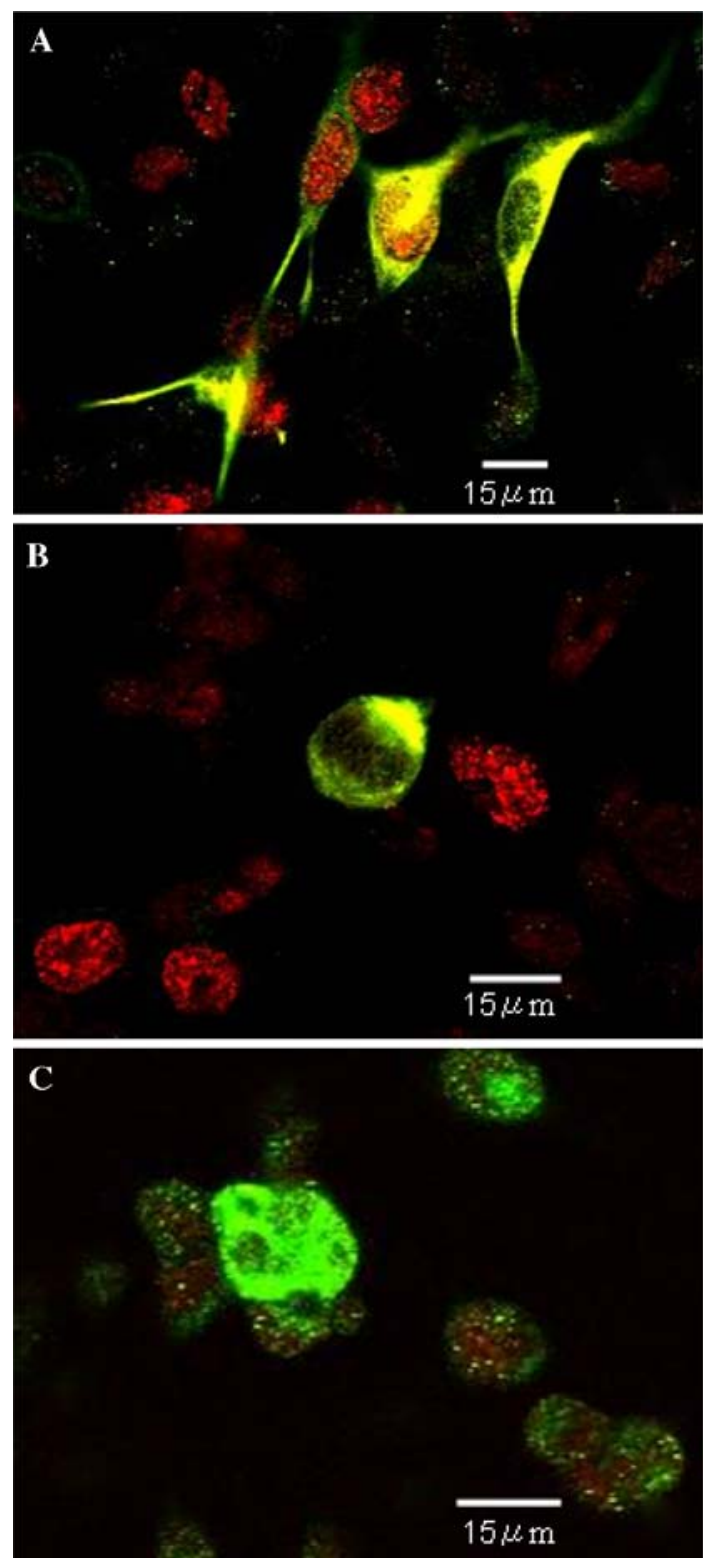

Fig. 3 Double immunostaining with antibodies for GFAP (green color) and proliferating cell nuclear antigen (PCNA) (red). a Filamentous pattern (wild type). b Polarized distribution pattern (wild type). The bipolar distribution was stained with both GFAP and PCNA (yellow), which plays a fundamental role in DNA replication and repair. c Aggregate or amorphous pattern (V87G). Cells showing this pattern were not stained with PCNA (green); therefore, these cells would be incapable of cell division

shown). The same experiment was repeated four times and the migration rates among these cells were compared. The migration rate of $\mathrm{V} 87 \mathrm{G}$ and $\mathrm{R} 88 \mathrm{C}$ were significantly greater than those of wild type and R416W $(P<0.01$; Fig. 5). However, the difference in migration rate between $\mathrm{V} 87 \mathrm{G}$ and $\mathrm{R} 88 \mathrm{C}$ or between wild type and R416W was not significant.

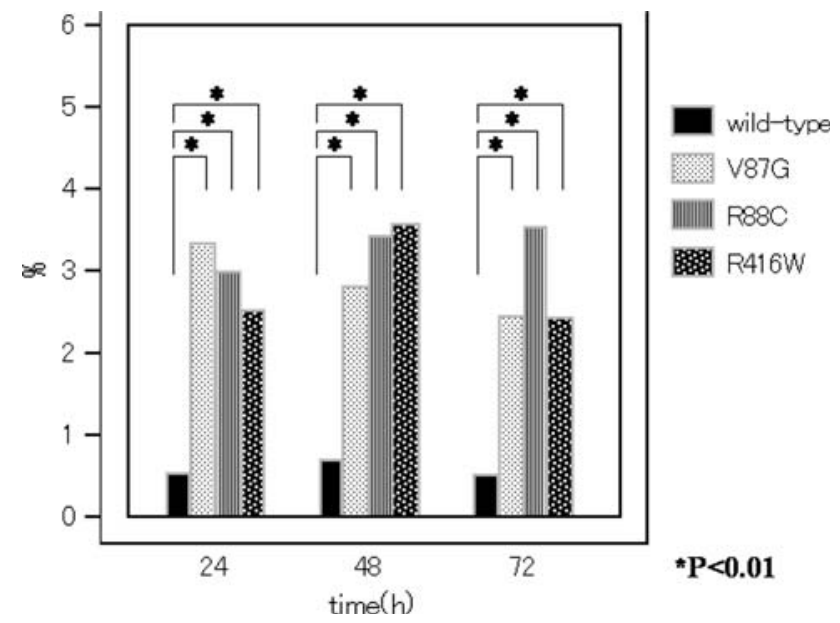

Fig. 4 Distribution of expression patterns of transfected cells. The $X$-axis indicates time and the $Y$-axis indicates the proportion of aggregate or amorphous (abnormal) pattern. In filamentous pattern, significant differences between wild-type GFAP and mutant GFAP are indicated as $* P<0.01$

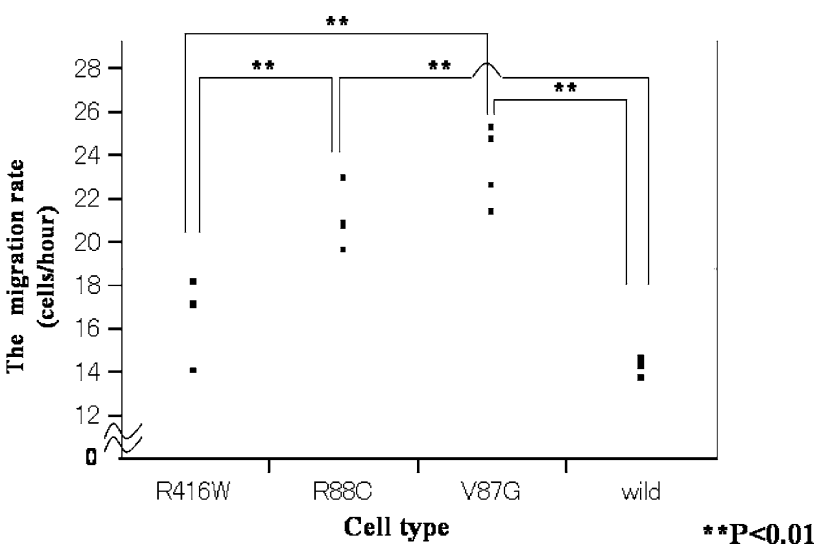

Fig. 5 Comparing the migration rate between transfected cell including wild-type and mutant GFAPs. The Tukey-Kramer HSD test was applied to the comparison of migration velocity between pairs of different plasmids

\section{Discussion}

After Brenner et al. (2001) reported that point mutations in GFAP were identified in patients with Alexander disease, a few reports were published on the expression patterns of GFAP point mutation ( $\mathrm{Li}$ et al. 2005; Hsiao et al. 2005; Perng et al. 2006). Li et al. (2005) demonstrated that vectors expressing mutant GFAP transiently transfected into adrenal carcinomaderived cells in which neither GFAP nor vimentin could form a normal filament network. Hsiao et al. (2005) also used adrenal carcinoma-derived cells and demonstrated that a mutant GFAP (R239C) altered the solubility and organization of GFAP networks. In 
our study, an astrocytoma-derived cell, mtU251, which expresses vimentin but not GFAP, was used as the host cell. In certain astrocytoma cells, vimentin is coexpressed and forms heteropolymer filaments with GFAP, which may be unsuitable to study the morphology of mutant GFAP (Quinlan and Franke 1983). However, we considered that using an astrocytomaderived cell line has a great advantage for investigating the interaction between astrocytes with mutant GFAP and other factors including extracellular components, and also for studying the fundamental effects of mutant GFAP on astrocytic functions in vitro.

Morphologically, the transfected cells could be classified into three patterns: the filamentous pattern, polarized distribution pattern and aggregate or amorphous pattern. The filamentous pattern could not be distinguished from normal GFAP filamentous architecture. Polarized distribution pattern, which was also stained with PCNA, was considered to perform a function in cell division. Therefore, both filamentous and polarized distribution patterns were regarded as normal structures. On the contrary, the aggregate and amorphous patterns in mutant GFAPs were considered abnormal structures and were incapable of cell division, because cells showing these patterns were not stained with PCNA, which shows immunoreactivity in the proliferative compartment of cells (Hall et al. 1990). These findings suggest that GFAP mutations might lead to alteration of the GFAP structure and are concerned with dysfunction of cell proliferation. However, the proportion of abnormal structure in the three kinds of mutant GFAPs was significantly larger than that in wild-type GFAP, although the level of aggregate formation in transfected cells was much lower than that reported by others (Hsiao et al. 2005; Perng et al. 2006). A plausible explanation for why most of the cells with mutant GFAP formed a normalappearing filamentous structure is that vimentin could play an important role in forming and stabilizing filamentous structures (Quinlan and Franke 1983).

Although the number of change of cell morphology was too small, the migration rate of mutant GFAPs altered. This finding suggests that the functional change of mutant GFAPs could develop before the morphological change. The migration rates of $\mathrm{V} 87 \mathrm{G}$ and $\mathrm{R} 88 \mathrm{C}$ cells were significantly higher than that of wild type, although there was no significant difference between R416W cells and wild-type cells. Astrocytoma cells may have different migration properties from normal astrocytes. However, V87G and R88C GFAP mutation might be able to alter the function of astrocytes and this functional alteration might vary depending on the domain in which the GFAP mutation is located. V87 and R88 locate in the helical rod domain or central helical domain in GFAP, which is considered important for interfilament network formation, filament assembly and stabilization of subunits (Fuchs 1996). The elevated proportions of abnormal GFAP structure in V87G and R88C mutant GFAP suggest that GFAP mutation in helical domains contributes to changing the filamentous architecture of GFAP to some degree (Fig. 2d, f). The higher migration rate of these cells compared to that of wild-type GFAP suggests that functional abnormalities of astrocytes may be induced before the formation of aggregation. The R416W GFAP mutation is located in the tail domain, which is conserved between all type III intermediate filament proteins and is thought to play a role in stabilizing protofibrillar interactions and filament diameter (Fuchs 1996). Furthermore, R416W GFAP would be expected to alter interactions with other cytoskeletal elements (Quinlan 2001) and be a cause of Alexander disease as well as a residue of the point mutation in the tail domain of desmin, which causes idiopathic dilated cardiomyopathy (Cary and Klymkowsky 1995; Li et al. 1999). Recently, Perng et al. (2006) demonstrated that R416W mutant GFAP disrupted normal filament assembly in vitro and that protein chaperones such as $\alpha \mathrm{B}$-crystallin and HSP27 specifically associated with GFAP aggregates in R416W mutant GFAP. In our study, the proportion of abnormal GFAP structure in R416W cells was also significantly larger than that in wild-type cells, while the migration rate of $\mathrm{R} 416 \mathrm{~W}$ cells were not significantly different from that of wild-type cells. These results suggest that intrafilament disruption could cause morphological alteration in the transfected cell with point mutation in the tail domain. Although the possibility that GFP-tag interferes with GFAP function in migration assay is not completely excluded, the interference could be disregarded to some extent because we compared the migration rate between GPF-tagged wild and mutant GFAPs in our study.

As for phenotype/genotype correlation, patients carrying V87G, R88C, and R416W mutations showed various clinical features with varied severities. V87G was found in a family with six affected patients, who showed varied severities of clinical features (Okamoto et al. 2002). R88C and R416W have also been reported to be mutations related to a broad clinical spectrum (Rodriguez et al. 2001; Kinoshita et al. 2003; Nobuhara et al. 2004; van der Knaap et al. 2006). The fact that the same mutations cause different phenotypes suggests that the phenotype could be influenced by not only structural and functional change induced by GFAP mutation per se, but also other components, 
e.g., other genetic factors, environmental factors, embryological factors and GFAP-regulating factors. Mitochondrial abnormality could be one aspect, because there are a few reports suggesting a relationship between Alexander disease and mitochondrial abnormality (Gingold et al. 1999; Schuelke et al. 1999; Nobuhara et al. 2004). Plectin, which is a member of the plakin family of cytolinker proteins and is localized at the cytoskeleton-plasma membrane interface, is another prospect. Recently, Tian et al. (2006) reported that the reduced level of total plectin in response to mutant GFAP expression in astrocytes would promote abnormal organization and aggregation of GFAP into Rosenthal fibers.

In conclusion, the results of the present study indicate that the GFAP point mutations lead to structural change and that the functional alteration depends on the domain in which the point mutation is located. Although it is premature to deduce firm conclusions concerning structure-function relationship from the limited number of mutations examined in this study, functional abnormalities in astrocytes may be induced before the formation of aggregation, especially in mutations located in the helical rod domain of GFAP. Since a variety of clinical features of Alexander disease with varying severities have been associated with each mutation, other factors that modify the clinical features of Alexander disease must be present. The identification of these factors will provide a clue to reduce the severity of Alexander disease and eventually lead to a therapy for Alexander disease.

Acknowledgments The authors are grateful to Ms. H. Uehori of the Department of Neurology and Gerontology, Kyoto Prefectural University of Medicine for excellent technical assistance. This work was supported in part by grants-in-aid for scientific research (C) (2) from the Ministry of Education, Culture, Sports, Science and Technology of Japan (15590902) and grants-in-aid from the Research Committee of CNS Degenerative Diseases, the Ministry of Health, Labour and Welfare of Japan.

\section{References}

Alexander WS (1949) Progressive fibrinoid degeneration of fibrillary astrocytes associated with mental retardation in a hydrocephalic infant. Brain 72:373-381

Aoki Y, Haginoya K, Munakata M, Yokoyama H, Nishio T, Togashi N, Ito T, Suzuki Y, Kure S, Iinuma K, Brenner M, Matsubara Y (2001) A novel mutation in glial fibrillary acidic protein gene in a patient with Alexander disease. Neurosci Lett 312:71-74

Brenner M, Johnson AB, Boespflug-Tanguy O, Rodriguez D, Goldman JE, Messing A (2001) Mutations in GFAP, encoding glial fibrillary acidic protein, are associated with Alexander disease. Nat Genet 27:277-286
Cary RB, Klymkowsky MW (1995) Disruption of intermediate filament organization leads to structural defects at the intersomite junction in Xenopus myotomal muscle. Development 121:1041-1052

Fuchs E (1996) The cytoskeleton and disease: genetic disorders of intermediate filaments. Ann Rev Genet 30:197-231

Gingold MK, Bodensteiner JB, Schochet SS, Jaynes M (1999) Alexander's disease: unique presentation. J Child Neurol 14:325-329

Gorospe JR, Naidu S, Johnson AB, Puri V, Raymond GV, Jenkins SD, Pedersen RC, Lewis D, Knowles P, Fernandez R, De Vivo D, van der Knaap MS, Messing A, Brenner M, Hoffman EP (2002) Molecular findings in symptomatic and pre-symptomatic Alexander disease patients. Neurology 58:1494-1500

Hall PA, Levison DA, Woods AL, Yu CC, Kellock DB, Watkins JA, Barnes DM, Gillett CE, Camplejohn R, Dover R, Waseem NH, Lane DP (1990) Proliferating cell nuclear antigen (PCNA) immunolocalization in paraffin sections: an index of cell proliferation with evidence of deregulated expression in some neoplasms. J Pathol 162:285-294

Hsiao VC, Tiao R, Long H, Der Perng M, Brenner M, Quinlan RA, Goldman JE (2005) Alexander-disease mutation of GFAP causes filament disorganization and decreased solubility of GFAP. J Cell Sci 118:2057-2065

Iwaki T, Kume-Iwaki A, Liem RK, Goldman JE (1989) AlphaB-crystallin is expressed in non-lenticular tissues and accumulates in Alexander's disease brain. Cell 57:71-78

Johnson AB, Bettica A (1989) On-grid immunogold labeling of glial intermediate filaments in epoxy-embedded tissue. Am J Anat 185:335-341

Kinoshita T, Imaizumi T, Miura Y, Fujimoto H, Ayabe M, Shoji $\mathrm{H}$, Okamoto $\mathrm{Y}$, Takashima H, Osame M, Nakagawa M (2003) A case of adult-onset alexander disease with Arg416Trp human glial fibrillary acidic protein gene mutation. Neurosci Lett 350:169-172

Li D, Tapscoft T, Gonzalez O, Burch PE, Quiñones MA, Zoghbi WA, Hill R, Bachinski LL, Mann DL, Roberts R (1999) Desmin mutation responsible for idiopathic dilated cardiomyopathy. Circulation 100:461-464

Li R, Messig A, Goldman JE, Brenner M (2002) GFAP mutation in Alexander disease. Int J Dev Neurosci 20:259-268

Li R, Johnson AB, Salomons G, Goldman JE, Naidu S, Quinlan R, Cree B, Ruyle SZ, Banwell B, D'Hooghe M, Siebert JR, Rolf CM, Cox H, Reddy A, Gutiérrez-Solana LG, Collins A, Weller RO, Messing A, van der Knaap MS, Brenner M (2005) Glial fibrillary acidic protein mutations in infantile, juvenile, and adult forms of Alexander disease. Ann Neurol $57: 310-326$

Meins M, Brockmann K, Ydav S, Haupt M, Sperner J, Stephani U, Hanefeld F (2002) Infantile Alexander disease: a GFAP mutation in monozygotic twins and novel mutations in two other patients. Neuropediatrics 33:194-198

Namekawa M, Takiyama Y, Aoki Y, Takayashiki N, Sakoe K, Shimazaki H, Taguchi T, Tanaka Y, Nishizawa M, Saito K, Matsubara Y, Nakano I (2002) Identification of GFAP gene mutation in hereditary adult-onset alexander's disease. Ann Neurol 52:779-785

Nobuhara Y, Nakahara K, Higuchi I, Yoshida T, Fushiki S, Osame M, Arimura K, Nakagawa M (2004) Juvenile form of Alexander disease with GFAP mutation and mitochondrial abnormality. Neurology 63:1302-1304

Okamoto Y, Mitsuyama H, Jonosono M, Hirata K, Arimura K, Osame M, Nakagawa M (2002) Autosomal dominant palatal myoclonus and spinal cord atrophy. J Neurol Sci 19:71-76 
Perng MD, Su M, Wen SF, Li R, Gibbon T, Prescott AR, Brenner M, Quinlan RA (2006) The Alexander Diseasecausing glial fibrillary acidic protein mutant, R416W, accumulates into Rosenthal fibers by a pathway that involves filament aggregation and the association of $\alpha \mathrm{B}$-crystallin and HSP27. Am J human genetics 79:197-213

Probst EN, Hagel C, Weisz V, Nagel S, Wittkugel O, Zeumer H, Kohlschutter A (2003) Atypical focal MRI lesions in a case of juvenile Alexander's disease. Ann Neurol 53:118-120

Quinlan RA (2001) Cytoskeletal catastrophe causes brain degeneration. Nat Genet 27:10-11

Quinlan RA, Franke WW (1983) Molecular interactions in intermediate-sized filaments revealed by chemical crosslinking. Heteropolymers of vimentin and glial filament protein in cultured human glioma cells. Eur $\mathrm{J}$ Biochem 16:477-484

Rodriguez D, Gauthier F, Bertini E, Bugiani M, Brenner M, N'guyen S, Goizet C, Gelot RS, Pedespan JM, Hernandorena X, Troncoso M, Uziel G, Messing A, Ponsot G, PhamDinh D, Dautigny A, Boespflug-Tanguy O (2001) Infantile Alexander disease: spectrum of GFAP mutations and genotype correlation. Am J Hum Genet 69:1134-1140

Sawaishi Y, Yano T, Takaku I, Takada G (2002) Juvenile Alexander disease with a novel mutation in glial fibrillary acidic protein gene. Neurology 58:1541-1543

Schuelke M, Smeitink J, Mariman E, Loeffen J, Plecko B, Trijbels F, Stockler-Ipsiroglu S, van den Hauvel L (1999) Mutant NDUFV1 subunit of mitochondrial complex I causes leukodystrophy and myoclonic epilepsy. Nature Genet 21:260-261
Shiihara T, Kato M, Honma T, Ohtaki S, Sawaishi Y, Hayasaka K (2002) Fluctuation of computed tomographic findings in white matter in Alexander's disease. J Child Neurol 17:227230

Shiroma N, Kanazawa N, Izumi M, Sugai K, Fukumizu M, Sasaki M, Hanaoka S, Kaga M, Tsujino S (2001) Diagnosis of Alexander disease in a Japanese patient by molecular genetic analysis. J Hum Genet 46:579-582

Shiroma N, Kanazawa N, Kato Z, Shimozawa N, Imamura A, Ito M, Ohtani K, Oka A, Wakabayashi K, Iai M, Sugai K, Sasaki M, Kaga M, Ohta T, Tsujino S (2003) Molecular genetic study in Japanese patients with Alexander disease: a novel mutation, R79L. Brain Dev 25:161-121

Suzuki Y, Kanazawa N, Takenaka J, Okumura A, Negoro T, Tsujino S (2004) A case of infantile Alexander disease with a milder phenotype and a novel GFAP mutation, L90P. Brain Dev 26:206-208

Tian R, Gregor M, Wiche G, Goldman JE (2006) Plectin regulates the organization of glial fibrillary acidic protein in Alexander disease. Am J Pathol 168:888-897

Tomokane N, Iwaki T, Tateishi J, Iwaki A, Goldman J (1991) Rosenthal fibers share epitopes with alpha-B-crystallin, glial fibrillary acidic protein, and ubiquitin, but not with vimentin: immunoelectron microscopy with colloidal gold. Am J Pathol 138:875-885

van der Knaap MS, Ramesh V, Schiffmann R, Blaser S, Kyllerman M, Gholkar A, Ellison DW, van der Voorn van Dooren SJM, Jakobs C, Barkhof F, Salomons GS (2006) Alexander disease. Ventricular garlands and abnormalities of the medulla and spinal cord. Neurology 66:494-498 